\title{
Wpływ dodatku wodoru do gazu osłonowego na właściwości dymów spawalniczych podczas spawania stali S235JR metodą TIG
}

\author{
Influence of hydrogen addition in shielding gas \\ on the properties of welding fumes during TIG method welding \\ of S235JR steel
}

\section{Streszczenie}

Proces spawania elektrodą nietopliwą nie generuje znacznych ilości związków niebezpiecznych zarówno dla środowiska, jak i dla spawaczy, nawet pomimo braku odciągu dymów i pyłów spawalniczych.

Badania złączy przeprowadzone podczas spawania elektrodą nietopliwą (GTAW) w osłonie mieszanki argonu z 5\% dodatkiem wodoru wykazały korzystny wpływ zarówno na trwałość i estetykę połączeń, jak i na warunki pracy spawaczy. Wodór w znacznym stopniu redukuje szkodliwe dla zdrowia pracowników związki chemiczne powstające w wysokiej temperaturze procesu, w tym szczególnie niebezpieczny mangan i jego tlenki.

W prawidłowo przygotowanych złączach istnieje uzasadnienie do stosowania wodoru jako dodatku do osłony gazowej ciekłego jeziorka przy spawaniu elektrodą nietopliwą zarówno stali austenitycznych, jak i ferrytycznych.

Słowa kluczowe: mieszanki osłonowe w spawalnictwie; stal niestopwa; mangan; wodór; GTAW

\begin{abstract}
The GTAW welding process does not generate significant amounts of hazardous compounds for both the environment and for welders, even in the absence of fume and welding dust extraction.

Testing of joints performed while welding with a non-consumable tungsten electrode (GTAW) in the argon blend with a $5 \%$ addition of hydrogen showed a beneficial effect on both the durability and aesthetics of joints as well as the working conditions of welders. Hydrogen significantly reduces harmful chemicals that arise at high temperature of the process, including particularly hazardous manganese and its oxides.

In well-prepared joints, there is justification for using hydrogen as an additive to the gas shield of the liquid pool when welding with the non-consumable electrode of both austenitic and ferritic steels.
\end{abstract}

Keywords: gas shield in welding; low alloy steel; manganese; hydrogen; GTAW

\section{Wstęp}

Dynamiczny rozwój procesów spawalniczych w ostatnich kilkudziesięciu latach oraz znaczny wzrost świadomości konsumentów co do szeroko rozumianej jakości wyrobów spawanych skłania producentów do stosowania technologii w sposób spełniający nie tylko wymagania techniczne, estetyczne i ekonomiczne, ale również warunki

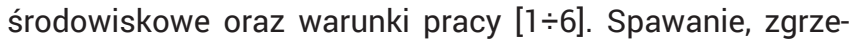
wanie czy lutowanie nierozerwalnie wiążą się z wysoką temperaturą niezbędną do prowadzenia procesu. Wysoka temperatura, wyładowania elektryczne, promieniowanie, pole elektromagnetyczne i hałas mają negatywny wpływ

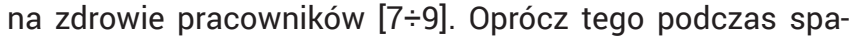
wania wydzielają się zanieczyszczenia w postaci pyłów i dymów, powstałych w czasie utleniania związków organicznych i nieorganicznych pochodzących z samego materiału łączonego, jak i z zanieczyszczeń wokół niego. Wszystko to sprawia, że spawaczy od lat zalicza się do grupy pracowników najbardziej narażonych na występowanie chorób zawodowych. Jak już wspomniano rozwój technologii spawalniczych pociąga za sobą dążenie do eliminowania z otoczenia pracy szkodliwych czynników. Stosowane współcześnie ciekłokrystaliczne, superczułe przyłbice oraz niepalne, przewiewne kombinezony, a także ognioodporne rękawice stanowią doskonałą ochronę indywidualną i znacznie ułatwiają pracę. Jednak do usuwania zanieczyszczeń w postaci pyłów i dymów spawalniczych zawierających szkodliwe, czasami

Mgr inż. Wojciech Sosnowski - PWSZ Ciechanów; dr hab. inż. Tadeusz Sałaciński, prof. PW - Politechnika Warszawska.

Autor korespondencyjny/Corresponding author. wojciech.sosnowski@pwszciechanow.edu.pl 
nawet trujące substancje stosowane są zwykle środki mechanicznego odciągania stanowiskowego i centralnego. Ta metoda jest najpowszechniej stosowana, ponieważ usuwa zanieczyszczenia każdego rodzaju, bez względu na skład chemiczny. Odciągi mechaniczne są najczęściej stosowane z tej przyczyny, że póki co nie ma lepszego sposobu, ale każdy, kto chociaż raz widział pracę na wydziale spawalni potwierdzi, że nie jest to metoda doskonała. Nie ma możliwości odebrania wszystkich produktów, które spalają się w wysokiej temperaturze. Dodatkowo spawanie skomplikowanych konstrukcji powoduje zawirowania emitowanych dymów, przez co odciągnięcie ich staje się praktycznie niemożliwe. Wszystko to powoduje, że szkodliwe składniki powstające w procesie są wdychane przez pracowników.

Celem przeprowadzonych badań było określenie wpływu wodoru zawartego w mieszance osłonowej na bazie argonu na warunki pracy w czasie spawania stali ferrytycznych elektrodą nietopliwą. Przeprowadzone badania dowodzą, że kontrolowany, ściśle określony dodatek wodoru do osłony argonowej korzystnie wpływa zarówno na jakość połączeń, jak i znacznie redukuje szkodliwe związki emitowane w wysokiej temperaturze procesu.

\section{Substancje szkodliwe powstające podczas spawania}

W dymach spawalniczych występują bardzo szkodliwe związki, cząsteczki chromu i niklu, z których dla układu oddechowego najbardziej szkodliwy jest chrom, właściwie związki VI wartościowego chromu, powszechnie uznawane są za czynniki rakotwórcze. Stąd bardzo dużym zagrożeniem dla spawacza jest spawanie stali nierdzewnych, w których głównym składnikiem odpowiedzialnym za odporność na korozję jest właśnie chrom. Podobnie wysoka temperatura przy cięciu i spawaniu plazmowym powoduje powstawanie szkodliwych tlenków azotu. Podczas spawania stali niskowęglowych tworzy się tlenek żelaza w postaci cząsteczek stałych (pyłu), które zwiększają ryzyko zachorowania na pylicę. Przy spawaniu mogą powstawać także inne szkodliwe substancje, jak np. związki fluoru i manganu [10,11].

W metodzie MIG i TIG jako gazy ochronne stosuje się argon i hel $[12,13]$. Gazy te same w sobie jako gazy szlachetne, nie są w najmniejszym stopniu niebezpieczne, ale mogą w niewietrzonych pomieszczeniach wypierać z powietrza tlen, co może doprowadzić do zasłabnięcia spawacza. Do spawania metodą MAG stosuje się jako gaz ochronny dwutlenek węgla lub coraz częściej jego mieszanki z argonem. W otoczeniu łuku spawalniczego część gazu ochronnego reaguje z powietrzem i wytwarza zwiększoną ilość tlenku węgla (CO), którego nie da się oddzielić pochłaniaczem gazu. Jeśli wentylacja jest mało skuteczna, należy kontrolować poziom tlenu i stosować systemy bezpośredniego zasilania w powietrze. Idąc dalej, powszechnie stosowane druty spawalnicze stosowane przy spawaniu metodą MAG zawierają znaczny dodatek manganu lub krzemu, co oznacza, że podczas spawania znacznie podwyższa się stężenie tlenków tych pierwiastków. Podczas spawania aluminium powstają nie tylko tlenki, ale również - na skutek emisji przez łuk spawalniczy promieni ultrafioletowych rozbijających cząsteczki tlenu - tworzy się ozon, czyli trójatomowy tlen. Ozon jest również wytwarzany podczas spawania stali nierdzewnej metodą TIG. Szkodliwe działanie ozonu polega na jego bardzo silnych właściwościach utleniających i wysokiej reaktywności chemicznej. Wchłonięty przez organizm człowieka, uszkadza nabłonki, tkanki, upośledza układ odpornościowy, wywołuje alergie, choroby nowotworowe, a wdychanie go w dużych stężeniach może prowadzić nawet do śmierci. Dwutlenki i tlenki azotu to związki powstające podczas spawania wysokim natężeniem prądu i w wysokiej temperaturze, w reakcji z tlenem z powietrza. W dużym stężeniu są bardzo niebezpieczne dla dróg oddechowych.

W gruncie rzeczy nie ma znaczenia czy spawana jest stal nierdzewna czy zwykłej jakości, elektrodą otuloną czy MAG, TIG czy plazmą, zawsze powstają opary spawalnicze, które zawierają zanieczyszczenia w postaci cząsteczek pyłu i dymy. Pokreślić należy fakt, że na działanie omawianych substancji najbardziej narażają metody spawania ręcznego: EO, MIG/MAG i TIG.

O ile przy spawaniu palnikiem gazowym oraz elektrodą otuloną możliwe jest wyłącznie pasywne oczyszczanie środowiska spawania za pomocą mechanicznych odciągów, to spawanie elektrodą nietopliwą (GTAW) i topliwą (GMAW) w osłonie reaktywnych mieszanek osłonowych na bazie argonu daje możliwość zastosowania takiej mieszanki, która częściowo utleni lub zredukuje szkodliwe substancje. Odpowiednio skomponowane mieszanki osłonowe nie tylko poprawiają właściwości techniczne i estetyczne połączeń, ale dodatkowo w sposób aktywny zmniejszają ilość szkodliwych substancji powstających w wysokiej temperaturze procesu spawania. Mając tego świadomość, warto zastanowić się nad metodami neutralizowania szkodliwych dymów, aby w czasie samego procesu spawania ograniczyć wydzielanie toksycznych związków lub by były usuwane wówczas kiedy powstają, czyli w reakcjach chemicznych zachodzących w wysokiej temperaturze łuku spawalniczego.

Wieloletnie obserwacje procesów potwierdzają, że zastosowanie trójskładnikowej mieszanki M23 $\left(\mathrm{Ar}+\mathrm{CO}_{2}+\mathrm{O}_{2}\right)$ do osłony jeziorka ciekłego metalu w czasie spawania metodą MAG pozwala na znaczne zredukowanie składników dymów spawalniczych. Dodatkowo istnieje tu bardzo duża możliwość wyboru różnorodnych mieszanek zarówno dwu, jak i trzyskładnikowych, pozwalających na jednoczesną poprawę parametrów spawalniczych, jak i warunków środowiskowych spawania.

Nieco inaczej jest ze spawaniem w osłonie gazów metodą GTAW, gdzie nie odnotowuje się znacznej emisji szkodliwych substancji. Dzieje się tak dlatego, że proces nie jest wysokowydajny i nie jest topiona duża ilość metalu, ale jednocześnie niska wydajność sprawia, że spawacz pozostaje dłuższy czas nad złączem. Ponadto metoda ta jest stosowana bardzo często do łączenia elementów ze stali stopowych, z dużą zawartością takich pierwiastków jak, np.: chrom, nikiel, mangan, molibden czy niob, które są szczególnie niebezpieczne w połączeniu np. z tlenem.

Ze względu na swój charakter spawanie TIG nie pozwala na stosowanie mieszanek ochronnych argonu z dodatkiem dwutlenku węgla ani tlenu. Obecnie do spawania austenitycznych stali nierdzewnych może być stosowana jedynie mieszanka argonu z niewielkim dodatkiem wodoru, który spełnia bardzo podobną funkcję jak tlen dodany do osłony w czasie spawania elektrodą topliwą. Natomiast stale ferrytyczne są spawane w osłonie czystego argonu, ze względu na powszechne przekonanie o niebezpieczeństwie powstawania zwłocznych pęknięć wodorowych.

W czasie badania wpływu dodatku wodoru do osłony argonowej na jakość złączy ze stali o strukturze ferrytycznej spawanych GTAW zauważono, że dymy spawalnicze wydobywające się znad spoiny mają nieznacznie jaśniejszą barwę, mniej się kłębią i nieco inaczej rozkładają nad powierzchnią materiału spawanego. Założono, że mieszanka argonu z wodorem ze względu na większą energię łuku eliminuje węglowodory pochodzące z zanieczyszczeń wokół złącza. 
W celu zweryfikowania redukujących właściwości wodoru zawartego w mieszance osłonowej przeprowadzono szczegółowe badania otoczenia spawania elektrodą nietopliwą.

\section{Wyniki badań}

W artykule przedstawiono wyniki badań ekspozycji zawodowej na czynniki szkodliwe dla zdrowia w środowisku pracy spawaczy w przedsiębiorstwie produkującym konstrukcje stalowe. Pomiary przeprowadzono 10 marca 2017 roku, 8-godzinny dzień pracy, próbki pobrano w godz. porannych (8:00-10:30), zanim uniosły się pyły z innych wydziałów produkcyjnych. Pomieszczenie spawalni jest ogrzewane centralnie, temperatura jaka panowała w dniu pomiarów to $17 \div 18$ ${ }^{\circ} \mathrm{C}$ i wilgotność $56 \%$. Pomiary zapylenia tlenku krzemu $\left(\mathrm{SiO}_{2}\right)$, tlenków żelaza $\left(\mathrm{Fe}_{2} \mathrm{O}_{3}\right)$, manganu i jego związków nieorganicznych $\left(\mathrm{Mn}\right.$ i $\left.\mathrm{MnO}_{2}\right)$ przeprowadzono metodą dozymetrii indywidualnej i pobierane były przez 150 min. Pomiary tlenku węgla (CO), tlenku azotu (NO), dwutlenku azotu $\left(\mathrm{NO}_{2}\right)$ i ozonu $\left(\mathrm{O}_{3}\right)$ przeprowadzono metodą stacjonarną w czasie $35 \mathrm{~min}$. Próbki pobrano podczas spawania metodą GTAW, detali ze stali S235JR przy wszystkich wykonywanych czynnościach.

Parametry spawania (tabl. I) były dobierane na podstawie zaleceń technologicznych oraz wizualnej oceny jakości spoin, dla każdej osłony oddzielnie. Parametry ustalono na podstawie głębokości wtopienia, kształtu lica oraz występowania ewentualnych lokalnych podtopień krawędzi spawanych wyrobów, tak by mieściły się minimum w klasie

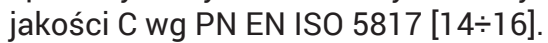

Do przeprowadzenia badań utworzono dwa stanowiska do prób, oddalone od siebie o 15 m, w sposób uniemożliwiający mieszanie się dymów. Na stanowisku nr 1 - spawanie elektrodą nietopliwą w osłonie mieszanki 95\% $\mathrm{Ar}$ i $5 \% \mathrm{H}_{2}$, na stanowisku nr 2 - gdzie spawano elektrodą nietopliwą w osłonie $100 \% \mathrm{Ar}$.
Eksperyment przeprowadzono w warunkach warsztatowych, w czasie wykonywania dużej ilości złączy o małej długości. W celu wyselekcjonowania jak największej ilości szkodliwych składników pyłów i dymów spawalniczych w środowisku pracy spawacza wyłączono wentylację mechaniczną zarówno ogólną, jak i stanowiskową. Spawacze wykonywali krótkie złącza po ok. $20 \mathrm{~mm}$ każde, z blachy zimnowalcowanej grubości $3 \mathrm{~mm}$ oraz pręta ciągnionego o średnicy $10 \mathrm{~mm}$. W czasie próby wykonano spoinę o sumarycznej długości ok. $930 \mathrm{~cm}$ na stanowisku pierwszym i ok. $860 \mathrm{~cm}$ na drugim. Pospawane detale odkładano w miejsce oddalone od stołu spawalniczego o ok. $1 \mathrm{~m}$, tak, żeby dodatkowe zadymienie uwalniane podczas stygnięcia wyrobów również uwzględniono w pomiarach.

Otrzymane wyniki badań (tabl. II) wskazują, że na żadnym stanowisku nie odnotowano przekroczenia dopuszczalnych stężeń większości czynników szkodliwych dla zdrowia spawaczy. Jedynym wyjątkiem jest przekroczenie NDS manganu i jego związków nieorganicznych w przeliczeniu na $\mathrm{Mn}$, frakcja respirabilna o blisko $26 \%$. Na obydwu stanowiskach zanieczyszczenie było znacznie poniżej wartości dopuszczalnych, pomimo tego, że wentylacja w czasie pobierania próbek była wyłączona. Porównując otrzymane podczas badania wartości, stwierdzono około dwukrotnie niższe stężenia najbardziej szkodliwych związków $\left(\mathrm{SiO}_{2}, \mathrm{Mn}\right.$ i $\mathrm{MnO}_{2} \mathrm{i} \mathrm{Fe}_{2} \mathrm{O}_{3}$ ) na stanowisku nr 1, czyli tam, gdzie zastosowano dodatek wodoru do mieszanki osłonowej. Pozostałe czynniki (CO, $\mathrm{NO}, \mathrm{NO}_{2} \mathrm{i} \mathrm{O}_{3}$ ) na obydwu stanowiskach były na porównywalnym poziomie.

Eksperyment wykazał przekroczenie dopuszczalnych wartości dla frakcji respirabilnej manganu oraz jego tlenków $\left(0,063 \mathrm{mg} / \mathrm{m}^{3}\right)$ w trakcie spawania metodą TIG stali niestopowej w technologicznie zalecanej osłonie czystego argonu. W tych samych warunkach na stanowisku spawania z dodatkiem wodoru było $0,038 \mathrm{mg} / \mathrm{m}^{3}$, znacznie poniżej wartości dopuszczalnych $\left(0,05 \mathrm{mg} / \mathrm{m}^{3}\right)$ zgodnie

Tablica I. Parametry procesu spawania próbek testowych

Table I. Welding process parameters of samples

\begin{tabular}{|c|c|c|c|c|c|}
\hline Stanowisko & Natężenie prądu [A] & Napięcie łuku [V] & $\begin{array}{c}\text { Prędkość spawania } \\
{[\mathbf{m m} / \mathbf{m i n}]}\end{array}$ & $\begin{array}{c}\text { Energia liniowa } \\
{[\mathbf{k J} / \mathbf{m m}]}\end{array}$ & Gaz osłonowy \\
\hline 1 & 98,0 & 10,7 & 230 & 0,164 & $95 \% \mathrm{Ar}+5 \% \mathrm{H}_{2}$ \\
\hline 2 & 118,0 & 9,8 & 215 & 0,194 & $100 \% \mathrm{Ar}$ \\
\hline
\end{tabular}

Tablica II. Zbiorcze wyniki badania substancji szkodliwych na spawalni

Table II. Collective results of testing harmful substances at the welding shop

\begin{tabular}{|c|c|c|c|c|c|}
\hline \multicolumn{4}{|c|}{$\begin{array}{l}\text { Ekspozycja zawodowa na czynniki szkodliwe dla zdrowia w środowisku pracy. } \\
\text { Data badania: } 10.03 .2017\end{array}$} & \multicolumn{2}{|c|}{$\begin{array}{l}\text { Pomiar stężenia na stanowisku } \\
\text { pracy: }\end{array}$} \\
\hline \multirow{2}{*}{ Lp. } & \multirow{2}{*}{\multicolumn{2}{|c|}{ Opis substancji }} & NDS ${ }^{1)}$ & $n r 1\left(\mathrm{Ar}+5 \% \mathrm{H}_{2}\right)$ & nr $2(100 \% \mathrm{Ar})$ \\
\hline & & & \multicolumn{3}{|c|}{$\left[\mathrm{mg} / \mathrm{m}^{3}\right]$} \\
\hline \multirow{2}{*}{1} & \multirow{2}{*}{$\begin{array}{l}\text { Pyły zwierające } \mathrm{SiO}_{2} \\
\text { od } 2 \% \text { do } 50 \%\end{array}$} & - frakcja wdychalna & 4,0 & $\underline{0,30}$ & 0,73 \\
\hline & & - frakcja respirabilna & 1,0 & $\underline{0,08}$ & 0,10 \\
\hline \multirow{2}{*}{2} & \multirow{2}{*}{$\begin{array}{c}\text { Mangan } \\
\text { i jego związki nieorganiczne }\end{array}$} & - frakcja wdychalna & 0,2 & $\underline{0,042}$ & 0,082 \\
\hline & & - frakcja respirabilna & 0,05 & $\underline{0,038}$ & 0,063 \\
\hline 3 & Tlenek żelaza & - frakcja respirabilna & 5,0 & $\underline{0,262}$ & $\underline{0,550}$ \\
\hline 4 & Tlenek węgla & $\mathrm{NDSCh}^{2)}$ w powietrzu & 23 & 2,53 & 2,53 \\
\hline 5 & Tlenek azotu & NDSCh w powietrzu & 3,5 & $<0,13$ & $<0,13$ \\
\hline 6 & Dwutlenek azotu & NDSCh w powietrzu & 0,7 & $<0,04$ & $<0,04$ \\
\hline 7 & Ozon & NDS w powietrzu & 0,15 & $<0,014$ & $<0,014$ \\
\hline
\end{tabular}


z PN-Z-04472:2015-10 i PN-Z-04472:2015-10/Ap1:2015-12. Dla frakcji wdychalnej nie odnotowano przekroczeń normy $\left(0,2 \mathrm{mg} / \mathrm{m}^{3}\right)$, ale i tak pomiar wykazał dwukrotnie mniejsze stężenie NDS na stanowisku $\mathrm{nr} 1\left(0,042 \mathrm{mg} / \mathrm{m}^{3}\right)$ w porównaniu do $0,082 \mathrm{mg} / \mathrm{m}^{3}$ uzyskanego na stanowisku $\mathrm{nr} 2$.

Ma to szczególne znaczenie, ponieważ w świetle badań prowadzonych w ostatnich kilku latach potwierdza się nadzwyczaj szkodliwy wpływ manganu i jego związków nieorganicznych na zdrowie ludzi. Metaliczny czysty mangan uznaje się za nieszkodliwy, natomiast jego związki z tlenem działają toksycznie - tym silniej im większy stopień utlenienia, np. tlenki manganu są wyraźnie mniej trujące niż jego nadtlenki. Długotrwałe narażenie na działanie manganu pochodzącego z oparów spawalniczych powoduje zaburzenia neurologiczne, spowolnienie ruchowe i trudności w mówieniu, objawy podobne do choroby Parkinsona. Ryzyko zatrucia manganem oceniła Międzyresortowa Komisja do spraw Najwyższych Dopuszczalnych Stężeń i Czynników Szkodliwych dla Zdrowia w Środowisku Pracy, określając maksymalne dopuszczalne stężenia manganu $\mathrm{i}$ jego związków, które jak już wspomniano, wynoszą dla frakcji wdychalnej $0,2 \mathrm{mg} / \mathrm{m}^{3}$ i dla frakcji respirabilnej $0,05 \mathrm{mg} / \mathrm{m}^{3}$. Istotne jest, że badania prowadzono na stali zwykłej jakości

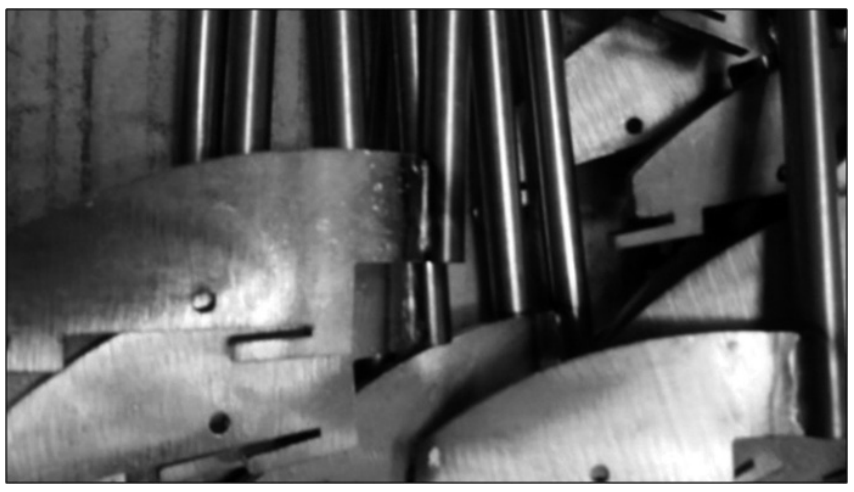

Rys. 1. Wyroby wykonane w trakcie eksperymentu

Fig. 1. Items made in the experiment

o zawartości Mn - 0,6\%. Należy się spodziewać, że proces może być tym bardziej niebezpieczny, jeśli wziąć pod uwagę spawanie stali nierdzewnych albo wysokowytrzymałych, drobnoziarnistych stali ferrytycznych o zawartości manganu przekraczającej $2 \%$. W tych gatunkach stali jest on powszechnie stosowany ze względu na swoje właściwości. Zwiększa twardość i wytrzymałość, a także odporność stali na ścieranie, częściowo zastępuje drogi nikiel.

\section{Wnioski}

Badania dowodzą, że dodanie w kontrolowanych warunkach, ściśle określonej ilości wodoru do mieszanki osłonowej jest korzystne nie tylko dla samego procesu spawania, efektów wizualnych w postaci gładkich, czystych spoin, ale także dla środowiska pracy spawacza. Nie mówimy tutaj o wodorze pochodzącym z powietrza czy wilgoci na źle przygotowanym złączu. Trzeba podkreślić konieczność właściwego przygotowania materiału przed spawaniem, a wówczas można uzyskać nienagannie wyglądające spoiny. Bardzo ważny aspekt, na który należy zwrócić uwagę, to fakt, że wysokoenergetyczny wodór redukuje szkodliwe związki z dymów i pyłów spawalniczych. Częściowe redukowanie toksyn już podczas samego procesu spawania oczyszcza atmosferę pracy spawacza, chroniąc go przed ich wpływem.

Na stanowisku chronionym mieszanką argonu z wodorem dopuszczalne stężenie manganu i jego związków dla frakcji wdychalnej nie było przekroczone, nawet pomimo wyłączonej wentylacji stanowiskowej i ogólnej.

Wyniki przeprowadzonych pomiarów wykazały przekroczenie najwyższego dopuszczalnego stężenia (NDS) manganu i jego związków nieorganicznych w przeliczeniu na $\mathrm{Mn}$ - frakcja respirabilna na stanowisku spawalniczym osłanianym czystym Ar.

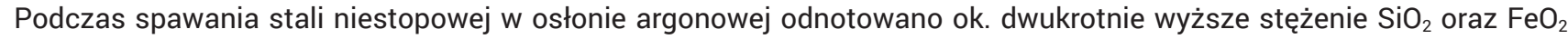
zarówno frakcji wdychalnej, jak i respirabilnej niż na stanowisku, na którym spawanie elektrodą nietopliwą było chronione mieszanką argonową z 5\% dodatkiem wodoru.

Pomiary stężeń pozostałych substancji nie wykazały przekroczenia wartości dopuszczalnych.

Zgodnie z wcześniejszymi przypuszczeniami w eksperymencie potwierdzono zasadność stosowania wodoru w mieszankach osłonowych na bazie argonu do spawania stali o strukturze ferrytycznej w celu ograniczenia emisji substancji szkodliwych w dymach spawalniczych.

\section{Literatura}

[1] Węglowski M., Chmielewski T., Kudła K.: Ocena wydajności spawania niskoenergetycznego procesu SpeedRoot w pozycji PG, Przegląd Spawalnictwa, vol. $83 \mathrm{nr} 12$, s. 26-30, 2011.

[2] Węglowski M., Chmielewski T., Kudła K.: Porównanie wybranych właściwości nowoczesnych spawalniczych inwertorowych źródeł energii przeznaczonych do spawania metodą MAG, Przegląd Spawalnictwa, vol. 81, nr 10, s. 81-83, 2009.

[3] Ferenc K., Cegielski P., Chmielewski T.: Technika spawalnicza w praktyce, Poradnik inżyniera konstruktora i technologa, Verlag Dashofer, Warszawa, 2015.

[4] Węglowski M., Chmielewski T., Kudła K.: Ocena wydajności spawania w wysoko wydajnym procesie SpeedUp oraz MAG Standard w pozycji przymusowej, Biuletyn Instytutu spawalnictwa w Gliwicach, vol. 54, nr 5, 199-201, 2010.

[5] Skowrońska B., Szulc J., Chmielewski T., Golański D.: Wybrane właściwości złączy spawanych stali S700 MC wykonanych metodą hybrydową plazma+MAG, Przegląd Spawalnictwa, vol. 89, nr 10, s. 104-111, 2017.

[6] Sałaciński T., Sosnowski W.: Wykorzystanie źródeł laserowych led do spajania cienkościennych elementów z blach nierdzewnych, Przegląd Spawalnictwa, vol. 88, nr 12, s. 10-14, 2016.

[7] Matusiak J., Wyciślik J.: Analiza środowiska pracy przy spawaniu metodą MAG elementów ze stali nierdzewnej i stali niestopowej z cynkową powłoką ochronną, Przegląd Spawalnictwa, vol. 87 nr 10, s. 92-97, 2015.

[8] Matusiak J., Wyciślik J.: Zdrowie i bezpieczeństwo przy produkcji spawalniczej. Biuletyn Instytutu Spawalnictwa nr 3/2009.

[9] Matczak W., Gromiec J.P.: Zasady oceny narażenia spawaczy na dymy i gazy, wyd. Instytut Medycyny Pracy im. J. Nofera, Łódź 2003.

[10] Ferenc K., Ferenc J.: Spawalnicze gazy osłonowe i palne, WNT, Warszawa, 2013.

[11] Bieńkowski M.: Filtry i pochłaniacze gazów stosowane w spawalnictwie, Magazyn Przemysłowy nr 6/2011.

[12] Chmielewski T., Golański D.: Napawanie brązu berylowego stellitem metodą MCAW, Przegląd Spawalnictwa, vol. 83 nr 10, s. 23-27, 2011.

[13] Drabarz M., Chmielewski T.: Wpływ tlenu resztkowego w gazie formującym na wybrane właściwości grani złącza stali 304L spawanego TIG orbitalnie, vol. $89 \mathrm{nr}$ 1, s. 45-50, 2017.

[14] Chmielewski T.: Projektowanie procesów technologicznych - Spawalnictwo, Oficyna Wydawnicza Politechniki Warszawskiej, Warszawa 2013

[15] Sałaciński T.: SPC-Statistical process control, Oficyna Wydawnicza Politechniki Warszawskiej, Warszawa 2015.

[16] Sałaciński T., Sosnowski W.: System nadzorowania jakości procesów spawalniczych zgodny z wymaganiami ISO $3834 \mathrm{w}$ oparciu o standardy ISO 9001. Cz. 2, Przegląd Spawalnictwa, vol. 87, nr 4, s. 10-13, 2015. 